\title{
B2C E-COMMERCE CUSTOMIZED LOGISTICS AREA INVENTORY ALLOCATION STRATEGY BASED ON CONSTRAINED CLUSTERING ALGORITHM
}

\author{
J.K. HUANG \\ School of Economics and Management, Beijing Jiaotong University, Beijing, 100044, China. \\ hjk03341@163.com
}

\begin{abstract}
Logistics network includes regional logistics network and urban logistics network. In this paper, the urban logistics network is taken as the research object. With the improvement of the consumption level of the residents, the attention to quality has become an important reference standard for consumers to choose e-commerce, which makes the electric business shift from "price war" to "service war". Compared with past purchases in physical stores, most consumers prefer to choose convenient and fast online shopping. As a result, the size of the online shopping market has increased rapidly. According to statistics, the growth rate of the online shopping market in the past five years is over $100 \%$, and the growth rate will slow down in the next few years, but it will still maintain steady growth. The importance of logistics for an e-business enterprise is obvious. The improvement and perfection of logistics distribution network is imminent. Scholars at home and abroad have studied this aspect for a long time. This research is based on the optimization of ecommerce logistics distribution network. By summing up the ideas and solutions proposed by researchers at home and abroad for this problem, and combining with the actual situation, a method of optimizing the B2C e-commerce logistics distribution network is designed. Considering the special traffic situation and the actual order demand in the city, the distribution area division, the distribution site stratification, the vehicle routing optimization and the logistics network optimization model are set up, and a combination of various methods is used to solve the problem.
\end{abstract}

Keywords-B2C electricity supplier; logistics network optimization; $K$ - central point clustering

\section{INTRODUCTION}

Logistics is an extremely critical link for B2C e-commerce enterprises, and an intermediate link between products and customers (Wu, 2015). At present, there are few researches on the layout of the national logistics network in the electricity supplier (Wang, 2015). More is the leadership, according to the historical sales data in the same period as well as their own experience in this field to make subjective assumptions, and then according to the actual situation to make local adjustments (Wu et al., 2018a). Due to the fast development of information of technology it has laid a solid foundation for the realization of information flow, business flow and capital flow in e-commerce (Lyu et al., 2014). But the most special logistics link in e-commerce has not been fully electronic (Hu et al., 2010). In addition to the small parts of software, electronic reading materials and music, most of the rest of the goods must be delivered, that is, logistics and distribution (Ke et al., 2018). The operation of logistics requires the actual operation of personnel and tools. Therefore, logistics plays an important role in a B2C ecommerce company. Distribution is a special and comprehensive form of activity in logistics. It is a combination of business flow and logistics, including business and logistics activities, and also a form of a number of functional elements in logistics (Wu et al., 2018b).

\section{ANALYSIS OF B2C E-COMMERCE LOGISTICE NETWORK}

E-commerce is developing with the development of network technology. There are many different definitions of e-commerce. As a new industry, e-commerce is in a stage of rapid development. Finally, the B2C enterprise is responsible for sending the goods they bought to their hands (Ghazy et al., 2011). E-commerce logistics distribution has become a bottleneck restricting the further development of B2C e-commerce industry in China (Donat et al., 2017). B2C e-commerce enterprises urgently need to optimize and expand their existing networks in order to take the lead in fierce market competition. The business parameter settings in the instance are shown in Table 1.

Table 1. Business parameter setting.

\begin{tabular}{cc}
\hline Parameter & $\begin{array}{c}\text { Numerical } \\
\text { value }\end{array}$ \\
\hline $\begin{array}{c}\text { The upper and lower limits of the } \\
\text { number of blocks }\end{array}$ & 5,9 \\
The upper and lower limit of block & 2000000, \\
orders & 9000000 \\
Inventory C & 6 \\
Customer loss ratio & 1.59 \\
Warehouse redundancy coefficient & 2.59 \\
Order average price & 325.6 \\
Service radius & $300,600,800$ \\
\hline
\end{tabular}




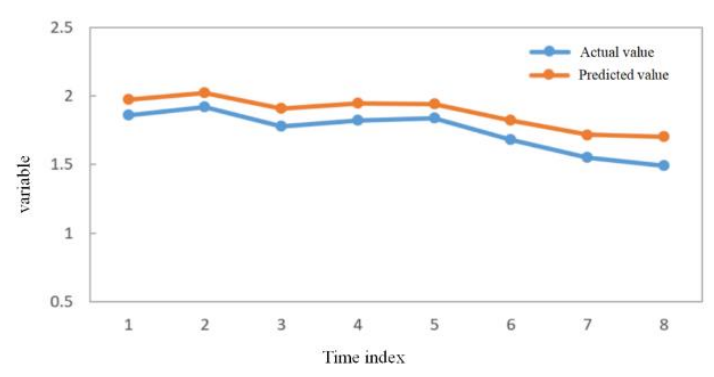

Figure 1. Prediction effect map.

The actual per capita order quantity and the predicted value generated in the PRE-1 are used as the $\mathrm{Y}$ axis variables, and the time as the $\mathrm{X}$ axis variable generation prediction effect map is compared, as shown in Fig. 1.

Because the development of electronic commerce in China is not long, the core data of consumer behavior is the chip of competition for e-commerce enterprises. There is a lack of convincing quantitative research in the field of e-commerce logistics network optimization. B2C e-commerce logistics network is a multi-level logistics system (Allaire et al., 2017). The location and construction of superstructure depend heavily on various factors of the underlying structure. In addition to the relatively fixed location of the top supply center, the location of all the other logistics nodes is based on the location of the next logistics nodes. The main factors that can affect the site selection process are: the order of the online shopping aggregated by the lower nodes and the specific distribution of each alternative logistics node after polymerization.

For each customer, each customer's demand and time window are shown in Fig. 2.

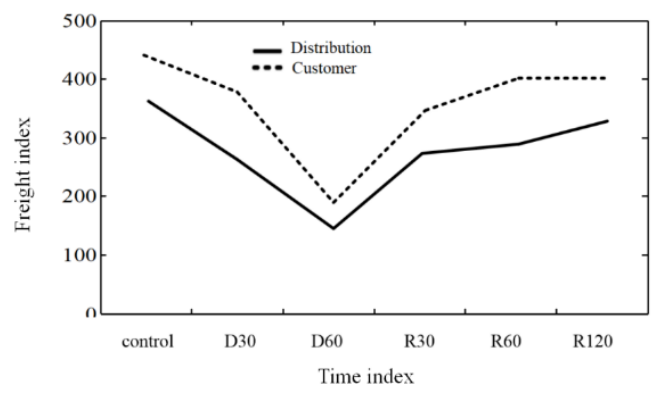

Figure 2. A distribution map to the customer.

The economic gravity model, developed by Newton's law of universal gravitation, has evolved from a number of versions of "the law of retail gravitation" and "the potential of urban and rural areas". The economic gravitational model, which is applied to the economic zoning, can be expressed as formula (1):

$$
D_{i}=a+\sum_{j=1}^{n} b_{j} p_{j}+r_{i} Y+u
$$

Among them, D represents the total population of each city, and a represents the quality difference of the city's population. By establishing different weighting values, $b$ is the GDP income of the region. $p$ represents the distance between cities. There are many ways to measure the distance. In reality, the actual distance or transportation between two cities is usually used. $\mathrm{j}$ measures the accessibility between two cities. The greater the value, the worse the accessibility between cities.

The distance between distribution points is preserved by two decimal places. The following table represents the distance between the distribution points. There are three types of vehicles, each of which has two cars. The specific information of the vehicle is shown in Table 2 below.

Table 2. Vehicle information.

\begin{tabular}{cccc}
\hline $\begin{array}{c}\text { Model } \\
\text { number }\end{array}$ & $\begin{array}{c}\text { Maxi- } \\
\text { mum } \\
\text { load } \\
\text { weight }\end{array}$ & $\begin{array}{c}\text { Maxi- } \\
\text { mum } \\
\text { driving } \\
\text { distance }\end{array}$ & Speed \\
\hline 1 & 200 & 140 & 30 \\
2 & 150 & 110 & 30 \\
3 & 80 & 600 & 30 \\
\hline
\end{tabular}

The comparison of functions, the comparison of the functions on the whole, the comparison results can only be on the whole, in order to express the relationship between the targets, the objective is compared and analyzed. The comparison results are shown in Fig. 3 below.

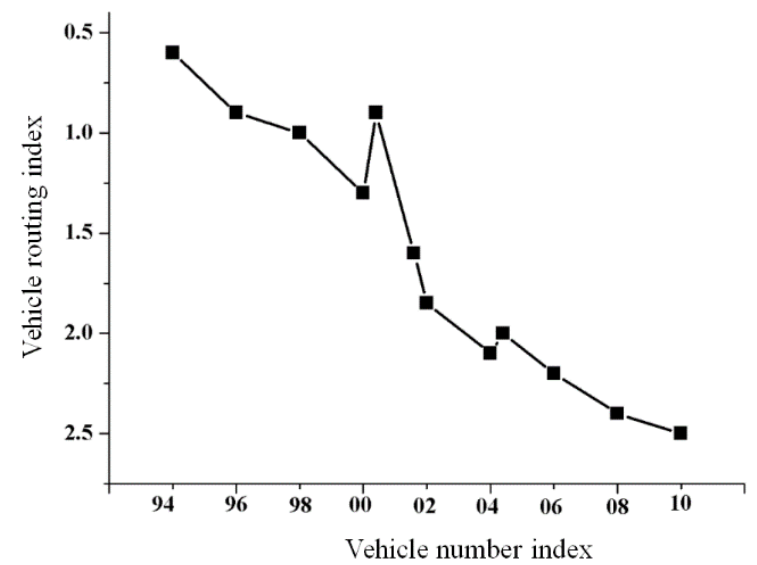

Figure 3. The relationship between vehicle routing and number of vehicles.

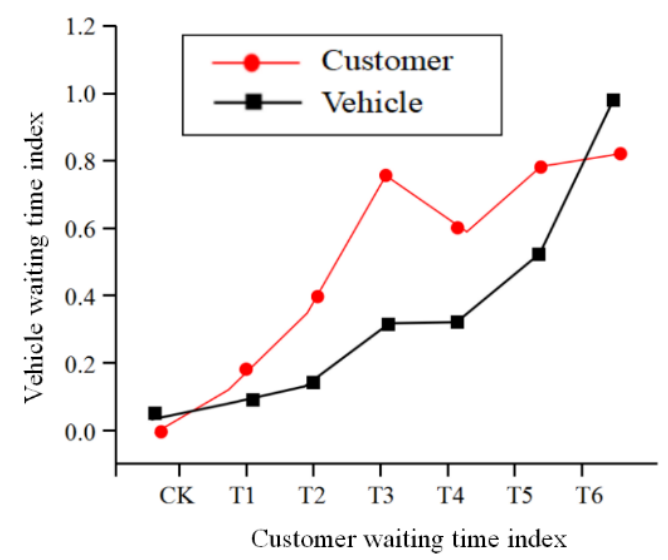

Figure 4. The relationship between the waiting time of the vehicle and the waiting time of the customer. 
Figure 4 is a graph of the waiting time and waiting time of the vehicle. It can be seen from the graph that there is an inverse relationship between the waiting time of customers and the waiting time of vehicles.

Clustering analysis is the process of dividing a data object into a subset. After division, the object is similar to one another in a certain attribute in the cluster and is different from the object attributes of other clusters. The core of the K-means algorithm is shown below.

Select a dataset containing $\mathrm{X}$ dimension data points, where i selects $T$ initial clustering centers:

$$
\begin{aligned}
& X_{i}=\left(X_{i 1}, X_{i 2}, X_{i 3}, \ldots, X_{i d}\right)^{T} \\
& X_{i d} \in\left(X_{\text {min }}, X_{\text {max }}\right)
\end{aligned}
$$

The Euclidean distance between each data object and the initial clustering center is calculated.

$$
P_{i}=\left(P_{i 1}, P_{i 2}, P_{i 3}, \ldots, P_{i d}\right)^{T}
$$

If you are satisfied, you have to go down.

$$
P_{g}=\left(P_{g 1}, P_{g 2}, P_{g 3}, \ldots, P_{g d}\right)^{T}
$$

The data set of prefecture level city is $W_{j}$, where $\mathrm{j}$ represents the dimension of data. $f$ represents the location attribute of the city i. $\mathrm{k}$ stands for the comprehensive level of the development of $\ln$ e-commerce in the city. Here, the concept of online shopping order quantity is used to describe it. The corresponding Eq. 5 is shown as follows:

$$
W_{j}=1+\frac{k \sum_{i=1}^{n} f_{i j} \ln f_{i j}}{\sum_{j=1}^{m}\left(1+k \sum_{i=1}^{n} f_{i j} \ln f_{i j}\right)}
$$

B2C e-commerce is a new retail business in the world. It combines traditional retail industry with developed network. So that consumers can choose their favorite products without leaving home, which greatly simplifies the process of selling goods. Although the optimization of B2C e-commerce logistics network and the optimization of logistics network in other industries all belong to the research area of logistics facilities address and logistics network layout. But if we simply use other industry logistics network optimization solutions to B2C e-commerce logistics network optimization. Will make the final B2C e-commerce logistics network optimization program lack of industry applicability. There is not only a lack of quantitative research on B2C e-commerce regional logistics services, but also the integration of various factors into the B2C enterprise regional logistics network.

\section{RESEARCH ON LOGISTICS NETWORK OPTIMIZATION OF B2C E-COMMERCE ENTERPRISE}

The order quantity of online shopping is the key factor to weigh the level of electricity supplier development and the location of self-logistics enterprises. To build a perfect e-commerce logistics network, we must first set the scope of each distribution node. However, online shopping orders, as the core data of e-commerce enterprises, are indispensable wealth in the era of big data. Through these data, e-commerce enterprises can analyze consumer behavior, and are controlled only by large enterprises such as Tmall and Jingdong. The so-called appropriate scope of action is the maximum distance that the logistics distribution node can deliver the goods to the customer in time and accurately. Some suppliers carry their goods to the B2C supply center, and the supply center will transport these commodities to the $\mathrm{B} 2 \mathrm{C}$ regional logistics distribution center in the way of centralized trunk transportation. Other suppliers direct their goods to the $\mathrm{B} 2 \mathrm{C}$ regional logistics distribution center.

From the two diagrams, we can see that the third operation and the fourth run are better than the others, and the cost and time are much smaller than the others. But the cost of the third time is slightly larger than the cost of the fourth time, and the fourth operation time is about the same as that of the third time. As shown in Fig. 5 and Fig. 6.

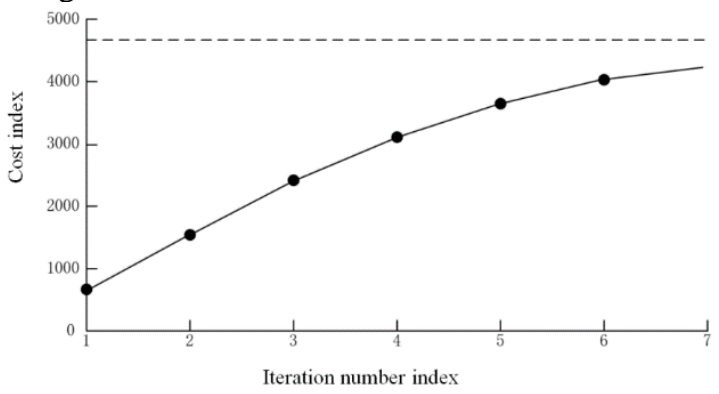

Figure 5. The convergence trend of the target factor.

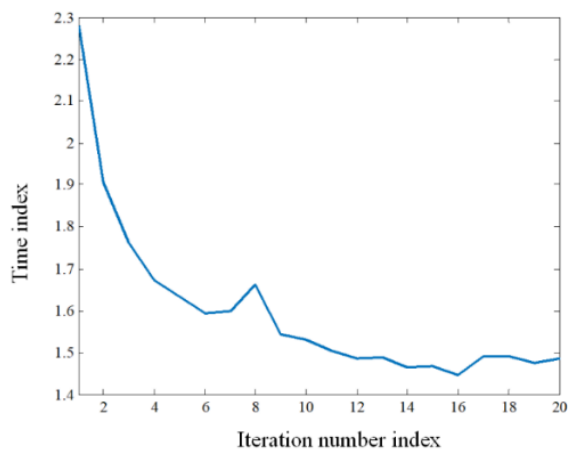

Fig. 6. The convergence trend of the objective function.

The optimization result information includes the number of regions in the logistics distribution network, the number and location of CDC. The number and location of CDDS, the number of vehicles, the route selection between nodes, and the total cost.

Table 3. Optimization results. Project Numerical value

\begin{tabular}{cc} 
Regional division & 30 \\
First level site & 6 \\
Two level site & 35 \\
Vehicle 1 & 10 \\
Vehicle two & 18 \\
Total cost & 88532 \\
\hline
\end{tabular}


A model for estimating online shopping orders through an electronic commerce platform can be expressed as:

$$
w(x, y, d)=\exp \left(-\left(\frac{d_{g}}{r_{g}}+\frac{d_{c}}{r_{c}}\right)\right)
$$

Among them, w represents the number of Internet users in a prefecture level city. $\mathrm{x}$ indicates the penetration rate of online shopping, that is, the number of online shopping users in the prefecture level city accounts for the proportion of netizens in the city. y represents the number of online shopping orders per person. $y$ indicates the influence of an e-commerce platform, that is, the share of the e-commerce platform in the B2C market.

Figure 7 is a fluctuation phenomenon in 5 stochastic experiments under uncertainty level. The robust model has good stability in dealing with uncertainties, and the value of the objective function fluctuates little. Moreover, the robustness model has lower standard deviation, which can better handle the disturbance phenomenon of uncertainty and is more conducive to the overall stability of the system.

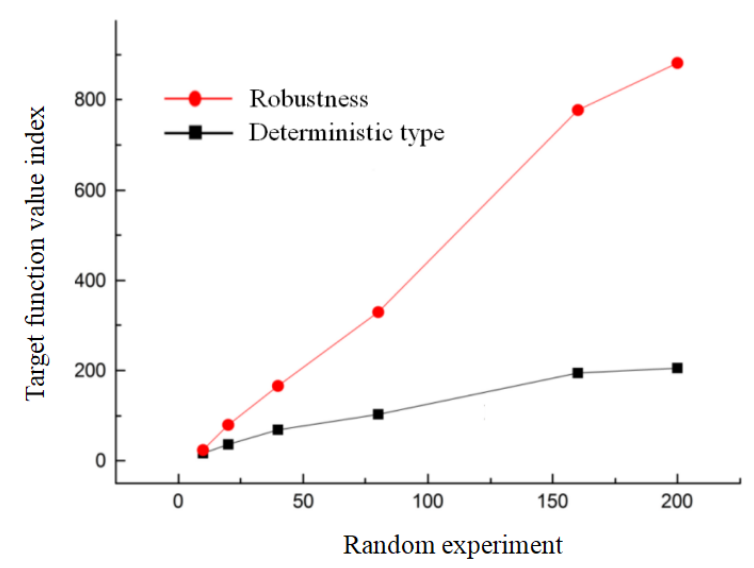

Figure 7. Objective function value wave diagram.

For a city's logistics distribution network hierarchy, we must first consider the size of the city. We also need to conduct a comprehensive survey of the online shopping users in the city to determine the logistics demand. The development of e-commerce in the cities of our country is very uneven. It involves the definition and design of logistics network hierarchy, architecture, node functions and network coverage. It is one of the core businesses of the B2C e-commerce industry. Its goal is to provide customers with satisfactory logistics services within a certain cost range.

$$
\begin{array}{r}
\operatorname{SelfAd}(x, y, d)=(1-t) \mid I(x, y)-I^{\prime}(x+d, y) \\
+t\left(\left|\nabla_{x} I(x, y)-\nabla_{x} I^{\prime}(x+d, y)\right|\right. \\
\left.+\left|\nabla_{y} I(x, y)-\nabla_{y} I^{\prime}(x+d, y)\right|\right)
\end{array}
$$

Type SelfAd: the number of vehicles owned by the distribution center. $I$ is the load of the vehicle. $t$ is the maximum running distance per car per day.
For each data object in the dataset, $\mathrm{C}$ traverses and calculates its 22 , whose distance is taken into consideration from the initial cluster center i. The distance parameter settings in traditional $\mathrm{K}$ - center point clustering are shown in this formula (8), where w represents the actual transport distance.

$$
\begin{gathered}
C\left(x, y, d^{(i)}\right)= \\
\sum_{(x, y) \in N(x, y)} w\left(x, y, d^{(i)}\right) \cdot \operatorname{Self} A d\left(x, y, d^{(i)}\right)
\end{gathered}
$$

In the process of its establishment, logistics nodes should make full use of the various existing conveniences and carefully choose the location of resettlement. To seek the logistics network structure which is in line with the development of the enterprise, it often requires the enterprise to make dynamic adjustment according to the situation of the current competitor, the market demand and the center of strategic development of the company in the actual operation. Goods from suppliers to B2C ecommerce Regional Logistics Center trunk line transportation. Goods in $\mathrm{B} 2 \mathrm{C}$ e-commerce in the regional logistics center warehousing, sorting and packaging. After packing, the order is transported from the $\mathrm{B} 2 \mathrm{C}$ ecommerce Regional Logistics Center to the B2C City Distribution Center trunk line. The self-built distribution network of powerful large enterprises has developed into an advanced and modern logistics distribution center with social reputation. Good transportation and warehouse storage, convenient distribution of goods are prerequisites for the development of distribution centers.

The functional elements of logistics distribution include stock preparation, storage, sorting and distribution, loading, distribution, transportation, service delivery and distribution processing.

(1) Stock up

It is the preparatory work and basic work of logistics distribution service, and collecting goods and goods quality inspection, transfer and settlement are all important aspects of stock preparation work. Stock preparation is the initial work for deciding the delivery success. If the cost of stocking is too high, the efficiency of distribution will be greatly reduced.

\section{(2) Storage}

There are two forms of storage and temporary storage. Reserve is a resource guarantee for distribution according to the requirements of distribution operation in a certain period, and warehouses can be set up separately near the distribution center. The adjustment of the structure of turnover reserve and insurance reserve is to adjust the storage structure and quantity according to the source of goods and the situation of arrival.

(3) Sorting and distribution

Sorting and distribution are special functional elements which are different from other logistics operations and are also important tasks for distribution. Therefore, sorting and distribution are the key elements to evaluate the level of distribution system of logistics enterprises.

The classification of logistics distribution can be divided into many types according to different standards. 
Here, we classify the logistics distribution according to the organizers of logistics distribution, roughly divided into these categories, as shown in Table 4.
Given the numeric HWt of clustering, D initial clustering centers are randomly generated for the initial $\mathrm{N}$ data objects.

Table 4. Classification of logistics distribution.

\begin{tabular}{ccc}
\hline Organizer & Advantage & Shortcoming \\
\hline Distribution Centre & Large scale and strong ability & Flexibility difference \\
Shop & Full of taste and high flexibility & Smaller scale \\
Warehouse & High flexibility & Small scale and poor specialization \\
manufacturing enterprise & High flexibility & Single variety \\
\hline
\end{tabular}

$$
H W t=\frac{\sum_{i=1}^{N} D_{i}(x)}{N}
$$

The remaining AI objects are traversed in turn. When traversing the I data object, $\mathrm{t}$ calculates the total cost function $\mathrm{D}$ with $\mathrm{Q}$ generation $\mathrm{t}$, and the expression of the cost function is shown in formula 10 .

$$
A I_{t}=\frac{\left(I_{t}+Q_{t}\right)+\left(I_{t}+Q_{t}-D_{t}\right)}{2}=I_{t}+Q_{t}-\frac{D_{t}}{2}
$$

In electronic commerce, the ownership of goods is transferred from the supply side to the demand side in the form of business flow from the moment of clicking on the purchase and sale contract, but the commodity entity has not been transferred automatically. The model of ecommerce logistics network must consider many constraints. First of all, we should consider the whole operation cost and minimize the cost. At present, Chinese B2C e-commerce enterprises mainly have two kinds of online shopping order delivery mode, one for enterprises to build their own logistics distribution mode. Such as Jingdong, excellence, fan and other market share accounted for a high proportion of the $\mathrm{B} 2 \mathrm{C}$ website. The other is outsourcing the third-party logistics distribution mode, which is the main order distribution mode adopted by many small and medium-sized B2C e-commerce enterprises. In the traditional trading process, in addition to non-physical delivery futures transactions, the general commodities must follow the corresponding logistics activities. That is, the buyer shall transfer the commodity entity to the buyer in the proper way and way.

\section{CONCLUSIONS}

This paper introduces the relationship between logistics distribution and $\mathrm{B} 2 \mathrm{C}$ e-commerce, showing that logistics distribution is an indispensable part of e-commerce. The logistics distribution line under e-commerce environment has many characteristics, such as many customer orders and scattered geographical location. The B2C ecommerce logistics network optimization and B2C ecommerce Regional Logistics Network Optimization as the research base. The improved two stage hybrid algorithm is not only simple, clear and flexible. Moreover, the improved genetic algorithm is used to solve the route optimization problem. The improved two stage hybrid algorithm has local optimization and overall optimization performance, greatly improving the quality of optimization, and greatly saving the cost of logistics distribution. The development of logistics and distribution is lagging behind, making logistics distribution a decisive factor in the development of B2C e-commerce. The optimization of distribution routes is an important part of logistics distribution.

\section{REFERENCES}

Allaire, G., C. Dapogny, R. Estevez, A. Faure and G. Michailidis, "Structural optimization under overhang constraints imposed by additive manufacturing processes: an overview of some recent results", Applied Mathematics and Nonlinear Sciences, 2(2), 385-402 (2017).

Donat, R. and S. López-Ureña, "High-accuracy approximation of piecewise smooth functions using the Truncation and Encode approach", Applied Mathematics and Nonlinear Sciences, 2(2), 367-384 (2017).

Ghazy, S.E. and A.H. Ragab ,"Removal of zinc ions from aqueous solutions by sorptive-flotation using limestone as a lowcost sorbent and oleic acid as a surfactant", Latin American Applied Research, 41(2), 99104 (2011).

$\mathrm{Hu}, \mathrm{K} . \mathrm{Y}$. and T.S. Chang, "An innovative automated storage and retrieval system for B2C e-commerce logistics", International Journal Advanced Manufacturing Technology, 48(1-4), 297-305 (2010).

$\mathrm{Ke}, \mathrm{Q}$., S. Wu, M. Wang and Y. Zou, "Evaluation of developer efficiency based on improved DEA model, Wireless Personal Communications, 102(4), 38433849 (2018).

Lyu, C., L. Li and T. Pan, "A smart B2C e-commerce system based on ACP approach". IEEE Intelligent. Systems, 29(4), 102-104 (2014).

Wang, L., "Research on the impact of e-commerce to logistics economy: An empirical analysis based on Zhengzhou airport logistics", International Journal of Security and Its Applications, 9(10), 275-286 (2015).

Wu, S., "A traffic motion object extraction algorithm", International Journal of Bifurcation and. Chaos, 25(14), (2015).

Wu, S., M. Wang and Y. Zou, "Research on internet information mining based on agent algorithm", Future Generation Computer Systems, 86, 598-602 (2018a). 
Wu, S., M. Wang and Y. Zou, "Sewage information monitoring system based on wireless sensor", Desalination Water Treat., 121, 73-83 (2018b)
Received: December 15th 2017

Accepted: June 30th 2018

Recommended by Guest Editor Juan Luis García Guirao. 